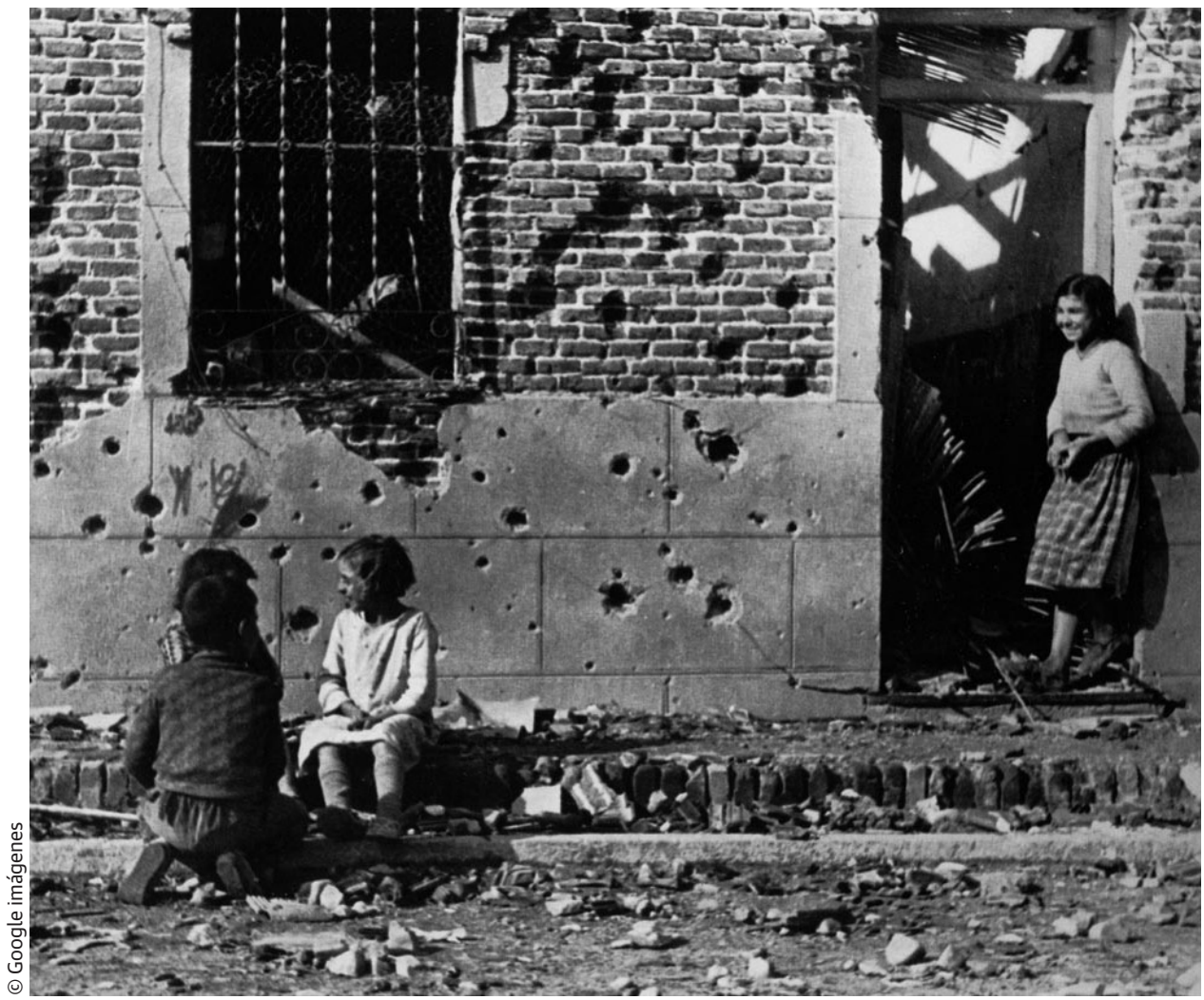

\title{
"PASEO POR UNA GUERRA ANTIGUA" (JUAN ANTONIO BARDEM, 1948-49): UNA CONTRAMEMORIA DE LA GUERRA CIVIL
}

\author{
"PASEO POR UNA GUERRA ANTIGUA" (JUAN \\ ANTONIO BARDEM, 1948-49): A COUNTER- \\ MEMORY OF THE SPANISH CIVIL WAR
}

Laure Pérez / laureperez@orange.fr

UNIVERSITÉ PARIS-SORBONNE,

ECOLE NORMALE SUPÉRIEURE DE PARIS 


\title{
RESUMEN
}

Este artículo pretende demostrar en qué medida Paseo por una guerra antigua (1948-1949), la práctica de segundo curso del Instituto de Investigaciones y Experiencias Cinematográficas (IIEC) en la que Juan Antonio Bardem rueda a un joven mutilado caminando por las ruinas de la Ciudad Universitaria de Madrid, constituye un intento pionero de desmontar los relatos oficiales de la Guerra Civil Española y rescatar la memoria de los vencidos. Filmar las ruinas del campus madrileño en aquellos años era un acto subversivo, puesto que el Régimen había emprendido su reconstrucción para borrar las huellas del Madrid republicano y de la Guerra Civil, resignificando por completo el recinto universitario. Por tanto, en Paseo por una guerra antigua, Bardem intenta reapropiarse de un espacio que en la época iba imponiéndose como uno de los "lugares de memoria" del franquismo. Esta película se vale de la función documental del cine para inmortalizar unas ruinas que simbolizan la República y la guerra, para preservarlas de la muerte simbólica que representa su reconstrucción. Mostrar esas ruinas en 1948-1949 equivale a "materializar" el pasado, a traerlo al presente de la posguerra, en un proceso que recuerda a los planteamientos sobre la Historia de Walter Benjamin, para proponer una visión alternativa de la contienda. Se trata de una visión teñida de una memoria íntima, ya que la película es un paseo no solo por las ruinas sino también por los recuerdos de este joven mutilado. En suma, Bardem propone una contramemoria de la Guerra Civil.

PALABRAS CLAVE

Paseo por una guerra antigua, Juan Antonio Bardem; Instituto de Investigaciones y Experiencias Cinematográficas (IIEC), Escuela Oficial de Cinematografía (EOC), Guerra Civil Española, memoria, Walter

Benjamin.

\begin{abstract}
This article aims to prove to what point Paseo por una guerra antigua (1948-1949) Juan Antonio Bardem's second year film project at the Instituto de Investigaciones y Experiencias Cinematográficas (IIEC) in which he shoots a young maimed veteran while walking through the ruins of Madrid's Ciudad Universitaria - constitutes an original attempt to dismantle the official version of the Spanish Civil War and to recover the memory of the defeated Republicans. Filming the ruins of Madrid's campus in those years was a subversive act, since the regime had begun to rebuild it in order to erase all traces of a Republican Madrid and of the Civil War, giving the University's area a whole new meaning. For this reason, in Paseo por una guerra antigua, Bardem tries to reclaim a space that, at the time, was becoming one of Franco's Regime's "spaces of remembrance". This film's role is to document this space in order to immortalize these ruins that symbolize the Spanish Republic and Civil War, to preserve them of the symbolical death of reconstruction. Filming these ruins in 1948-1949 is equivalent to "materializing" the past, of bringing it back to the present post-war period, through a process which brings Walter Benjamin's thoughts on History to mind, in order to propose an alternative vision of the Spanish Civil War. This vision is tinged with an intimate memory, since the film is a stroll not only through those ruins but also through the young maimed veteran's memories. In short, Bardem proposes a counter-memory of the Civil War.
\end{abstract}

KEYWORDS

Paseo por una guerra antigua, Juan Antonio Bardem, Instituto de Investigaciones y Experiencias Cinematográficas (IIEC), Escuela Oficial de Cinematografía (EOC), Spanish Civil War, Memory, Walter Benjamin. 


\section{INTRODUCCIÓN}

Juan Antonio Bardem (1922-2002) formó parte de la primera promoción del IIEC, la que entró en la escuela en el curso 1947-1948. Allí coincidió con Luis García Berlanga, Agustín Navarro y Florentino Soria. Bajo la iniciativa de Bardem (Bardem, 2002: 70-72)1, los cuatro alumnos se juntaron para rodar su práctica de segundo curso, Paseo por una guerra antigua. Esta unión les permitía acumular los escasos metros de película que correspondían a cada uno de ellos ${ }^{2}$. Sin embargo, la dirección de la práctica no fue conjunta. Bardem cuenta en sus memorias: "la película la dirigimos Luis y yo, después de haber fagocitado a Agustín y a Florentino" (2002: 70-72). Parece que el verdadero director de la película fue solo Bardem, según los testimonios de Agustín Navarro y Florentino Soria. Como narra Juan Francisco Cerón Gómez: "Navarro recuerda [...] que, durante el rodaje, casi siempre se imponía el criterio de Bardem a la hora de emplazar la cámara” (1998: 34) y Florentino Soria afirma que "la película tenía, sobre todo, la impronta de Bardem, y su tema no admitía que Berlanga firmara ninguno de sus característicos toques de humor. Navarro y yo, que admitíamos la indiscutible superioridad de los dos B, actuábamos más bien como ayudantes de dirección” (Cerón Gómez, 1998: 34). En efecto, el tema no es propicio al humor: la película se ambienta en las ruinas de la Ciudad Universitaria de Madrid en la posguerra y, en palabras de Bardem, el protagonista es "un hombre joven, un mutilado [que] recorre este 'paisaje después de una batalla' y recuerda” (Bardem, 2002: 70-72) ${ }^{3}$. La película fue rodada en 16 milímetros ${ }^{4}$ y montada en el domicilio de Bardem ${ }^{5}$. Según este, el proyecto era hacer "un experimento audiovisual" (2002: 70-72), sin diálogos, pero con sonidos de la batalla. Sin embargo, después de haber rodado la película, los cuatro alumnos se enteraron de que el IIEC no tenía la financiación necesaria para sonorizarla, por tanto, como reconoce Bardem, el "experimento audiovisual se quedó simplemente en visual" (2002: 70-72)6. Hoy en día, de la película solo se conservan fragmentos del negativo y de un copión, ambos sin montar.
Nuestro propósito en este artículo es comprobar la hipótesis que Juan Francisco Cerón Gómez formula acerca de Paseo por una guerra antigua: "aunque sea un ejercicio académico, es la primera película desde 1939 que se hizo en España sobre la Guerra Civil de acuerdo con la óptica de los vencidos" (Cerón Gómez, 1998: 33). Es preciso recordar que Bardem se había afiliado al Partido comunista clandestino a mediados de los años cuarenta7 ${ }^{7}$ Obviamente, en la película no aparecen signos claros de las ideas antifranquistas de

\footnotetext{
1 Bardem también habla de la película en su testimonio en el libro 50 años de la Escuela de cine (Llinás, 1999: 41-42).

2 Juan Francisco Cerón Gómez cuenta que: "La idea de realizar la práctica conjuntamente partió [...] de Bardem como modo de superar las limitaciones de material con las que había que realizarla: a cada alumno le correspondían tan solo cincuenta metros de película de 16 milímetros y de [este] modo pudieron contar con doscientos" (Cerón Gómez, 1998: 33-34). Florentino Soria confirma este dato en su testimonio en el libro de 50 años de la Escuela de cine (Llinás, 1999: 118).
}

3 Bardem también cuenta que el actor era un amigo suyo, de la época en la que estudiaba la carrera de Ingeniero Agrónomo: "Como yo jugaba al rugby con el equipo de Agricultura, un maldito domingo, jugando contra arquitectura, este amigo cayó en mala postura en un placaje y en la mêlée subsiguiente le partimos la pierna. Le trataron la fractura y le escayolaron. Pero esa escayola debieron de hacérsela mal y al final apareció la gangrena. Tuvieron que cortarle la pierna por debajo de la rodilla" (Bardem, 2002: 70-72).

4 Francisco Llinás recuerda que, dada "su integración dentro de la Escuela de Ingenieros Industriales", el IIEC tuvo que "aprovechar las instalaciones ya existentes en ella, que sólo permitían la producción de películas en formato de 16 milímetros, formato que no tenía ninguna implantación en la industria cinematográfica en España. El rodaje de películas en 16 milímetros no suponía un aprendizaje de las practicas utilizadas en la industria del cine, aunque si una aproximación a las técnicas del lenguaje cinematográfico" (Llinás, 1999: 14)

5 Según cuentan Juan Francisco Cerón Gómez en El cine de Juan Antonio Bardem (Cerón Gómez, 1998: 33) y el propio Bardem (2002: 70-72).

6 Bardem también cuenta: "A veces hicimos alguna proyección para nosotros mismos y yo me pasaba el tiempo imitando explosiones, tableteos de ametralladora, caída en picado, vuelos rasantes, etc. ¡Era cómico y ridículo a la vez!" (Bardem, 2002: 70-72).

7 Afiliación que le valdría ser detenido por la Brigada político-social en febrero de 1956, en pleno rodaje de Calle mayor, en el contexto de los disturbios en la Universidad de Madrid. Véase "Bardem Muñoz, Juan Antonio" (Monterde, 2011: 678-686). Antonio Castro insiste en los vínculos que existen entre la obra cinematográfica de Bardem y su labor como militante del PCE (Castro, 2013: 87). 
Bardem, pero en realidad el mero hecho de filmar las ruinas de la Ciudad Universitaria en un momento -el final de los años cuarenta- en el que ya se ha emprendido su reconstrucción y en el que el régimen intenta borrar las huellas de la Guerra Civil en Madrid es ya subversivo. $\mathrm{Pa}$ seo por una guerra antigua es un intento de reapropiación del espacio altamente simbólico de la Ciudad Universitaria por parte de un director comprometido con las ideas antifranquistas, y un intento de transmisión de una contramemoria de la contienda. Filmar las ruinas es una manera de "materializar" el pasado, de traerlo al presente de la posguerra para proponer una visión de la Guerra Civil distinta del relato oficial que impone el régimen. Se podría decir que Bardem es un "cineasta-historiador", en el sentido que Miguel Ángel Hernández Navarro le da a este concepto en su libro Materializar el pasado. El artista como historiador (benjaminiano) (2012).

\section{RESIGNIFICACIÓN DEL ESPACIO DE LA CIUDAD UNIVERSITARIA EN LA POSGUERRA}

Si el mero hecho de que Bardem filme las ruinas de la Ciudad Universitaria en 1948-1949 se puede considerar como un acto subversivo, es porque se trata de un espacio altamente simbólico. En la posguerra, el régimen franquista lleva a cabo una completa resignificación de este antiguo emblema de la cultura republicana y escenario de una de las batallas de la Guerra Civil.

La construcción de la Ciudad Universitaria de Madrid había sido un proyecto originado por la monarquía de Alfonso XIII, para mejorar las condiciones de la enseñanza superior, trasladando las instalaciones de la Universidad Central a un único recinto, inspirado en el modelo del campus norteamericano ${ }^{8}$. Las obras empezaron en 1929 bajo la dirección de la Junta Constructora de la Ciudad Universitaria. A partir de 1931 la República asumió el proyecto como si fuera suyo ${ }^{9}$ y en enero de 1933 se inauguró parte del edificio de la Facultad de Filosofia y Letras ${ }^{10}$. Tanto la Monarquía como la República veían en la Ciudad
Universitaria un símbolo de la modernización de España ${ }^{11}$. Al estallar la Guerra Civil, estaba muy avanzada o casi terminada la construcción de las facultades de Medicina, Farmacia, Odontología, el Hospital Clínico y la Escuela de Arquitectura (Chías Navarro, 1983: 138). El campus es el escenario de combates entre el 15 y el 23 de noviembre de $1936^{12}$, día en que Franco renuncia a tomar Madrid pero decide mantener sus tropas en la Ciudad Universitaria. Según Fernando Calvo González-Regueral, esta posición era "un absurdo táctico pero [tenía un] gran valor simbólico" (Calvo González-Regueral, 2012: 60); representa su "advertencia constante sobre Madrid" (2012: 60). El frente se estabiliza y empieza una guerra de trincheras y de minas que dura hasta el final de la contienda (2012: 394) ${ }^{13}$. Es por la Ciudad Universitaria por donde las tropas de Franco entran en Madrid, el 28 de marzo de 1939.

Los numerosos daños que se pudieron constatar en los edificios de la Ciudad Universitaria después de la guerra se debían a "los bombardeos, las minas y la ocupación por las tropas" (Chías Navarro, 1983: 114). Pablo Campos Calvo-Sotelo coin-

8 Respecto a la historia de la construcción de la Ciudad Universitaria, véase La Ciudad Universitaria de Madrid: Planeamiento y Realización (Chías Navarro, 1983); La Ciudad universitaria de Madrid (Bustos Moreno, 1988); 75 años de la Ciudad universitaria. Memoria viva de un campus trascendental (Campos Calvo-Sotelo, 2004) y La ciudad universitaria de Madrid, 80 años de Historia, (Fernández de Sevilla Morales, 2008).

9 Para Antonio Bonet Correa, "la República tomó como si fuera cosa suya el proyecto", (Bustos Moreno, 1988: 14). Según Pablo Campos Calvo-Sotelo, el cambio de régimen "no afectó a la continuidad de la Ciudad Universitaria" (Campos Calvo-Sotelo, 2004. 110).

10 Véase La Facultad de Filosofía y Letras de Madrid en la Segunda República. Arquitectura y Universidad durante los años 30 (LópezRíos Moreno y González Cárceles, 2008).

11 Para Antonio Bonet Correa, la Ciudad Universitaria era "un símbolo de la cultura moderna a la que [...] aspiraba España", "La Ciudad Universitaria de Madrid: Realidad y utopía de un proyecto para la modernización cultural de España" ", (Bustos Moreno, 1988: 1).

12 Respecto al tema de la Guerra Civil en el campus madrileño, véase La Guerra Civil en la Ciudad Universitaria (Calvo González-Regueral, 2012).

13 Las posiciones nacionales incluyen la Escuela de Arquitectura, la de Ingenieros Agrónomos, la Casa de Velázquez, el Palacete de la Moncloa, parte del parque del Oeste y el Hospital Clínico, desde el cual pueden dominar Madrid. En cuanto a los republicanos, están en la Facultad de Filosofía y Letras y en las de Medicina, Farmacia y Odontología. La actual avenida Complutense constituye el estrecho no man's land que separa los dos bandos. 
cide con Sofia Diéguez Patao ${ }^{14}$ al estimar que "se perdió el $40 \%$ de lo que se había erigido hasta julio de 1936" (Campos Calvo-Sotelo, 2004: 120). En palabras de Pilar Chías Navarro, "el paisaje quedó esquilmado, convertido en un páramo, en un erial desfigurado por trincheras y nidos de ametralladoras" (1983: 148).

Como señalan varios autores, en la inmediata posguerra no se emprendió en seguida la reconstrucción de la Ciudad Universitaria: se contempló la opción de trasladar la Universidad a Alcalá (Chías Navarro, 1983: 151) y de dejar las ruinas tal cual ${ }^{15}$, como en Belchite ${ }^{16}$. Carolina Rodríguez López insiste en la dimensión religiosa de estas ruinas (Rodríguez López, 2015: 87) ${ }^{17}$ que, en la óptica del Nuevo Régimen, simbolizaban el sacrificio heroico de los que allí lucharon por la redención y la resurrección de la Patria18. Según ella, "la ruina fue durante un tiempo el paisaje dominante y se usó como forma de revalorar la victoria franquista. Cicatrices heroicas, llagas en el espíritu nacional, motivos de recordación... con todos estos términos y aun muchos más el paisaje ruinoso era referido" (Rodríguez López, 2015: 85) ${ }^{19}$. Carolina Rodríguez López señala también que las ruinas podían ser instrumentos de propaganda, al ser designadas como culpables de la destrucción de la Ciudad Universitaria las "hordas marxistas" (Rodríguez López, 2004: 5).

Sin embargo, se opta por reconstruir y se crea una nueva Junta Constructora de la Ciudad Universitaria, presidida por Franco, en febrero de 1940 (Rodríguez López, 2004: 10). Como subrayan varios autores, la reedificación permite al régimen "iniciar su andadura histórica con símbolos de progreso y materialización práctica" (Rodríguez López, 2002: 223) y “ensalzar la figura del general Franco como constructor" (Diéguez Patao en Bustos Moreno, 1988: 56). A iniciativas del Departamento Nacional de Cinematografía (DNC) se ruedan dos cortometrajes documentales de propaganda, Trincheras de paz (1939) y Resurrección: Ciudad Universitaria (1940) (Del Amo, 1996: 853 y 794). Estas películas promocionan la reconstrucción de la Ciudad Universi- taria y exhortan a los españoles a participar en el sorteo de la Lotería Nacional que se celebra cada 11 de mayo para la financiación de las obras (Del Amo, 1996: 853 y 794).

Esta reconstrucción equivale a una resignificación del espacio universitario: el Nuevo Régimen se apropia los proyectos anteriores y les da un contenido conforme a su ideología ${ }^{20}$. Según Carolina Rodríguez López, "el espacio se resignificó acorde al contenido político del nuevo régimen. El trazado de la Ciudad Universitaria facilitaba la celebración de los eventos religiosos, deportivos y militares, tan afines al franquismo" (Rodríguez López, 2015: 85). Para esta autora,

14 "Destrucción, reconstrucción y nuevo carácter de la Ciudad Universitaria. Años cuarenta" (Bustos Moreno, 1988: 55).

15 "Es un deseo nacional el conservar en su estado actual total o parcialmente y aun realzándolo el escenario de la heroicidad de nuestro Glorioso ejército. Ello es perfectamente compatible con el trazado de circulación y ordenación del Plan General de la Ciudad Universitaria", "Cuestiones que se consideran de mayor urgencia", s.f. (Archivo Histórico de la Universidad Complutense de Madrid, Junta Constructora de la Ciudad Universitaria. Caja D1725), (Rodríguez López, 2002: 234). Antonio Bonet Correa explica que "para buen número de ideólogos del Movimiento, las ruinas heroicas de la guerra [...] no debían ser restauradas sino permanecer como símbolo de memoria eterna de un Régimen que nacía y se constituía en cruzada. El morbo arqueológico de estas ruinas tenía mucho que ver con el intento de fijación de una temporalidad bélica que negaba el futuro como realidad y se complacía en la proyección del pasado sobre el presente. Las ruinas venían a convertirse, de esta suerte, en poema permanentizado de violencia" "Espacios arquitectónicos para un nuevo orden", (Bonet Correa, 1981, citado por Chías Navarro, 1983: 151).

16 Belchite es un pueblo de la provincia de Zaragoza en el que se libró una de las batallas de la Guerra Civil. En los años 1940, Franco decidió dejar las ruinas tal cual, como recuerdo de la guerra, y construir un pueblo nuevo al lado. Véase "Vivre entre les ruines. Belchite, 1937-2014" (Michonneau, 2015).

17 Véase también, de la misma autora, "Usos políticos y académicos del espacio universitario..." (Rodríguez López, 2004: 4).

18 Pablo Campos Calvo-Sotelo escribe que, al terminar la guerra, la Ciudad Universitaria se había convertido en "una suerte de santuario donde homenajear a los héroes caídos en el frente" (Campos Calvo-Sotelo, 2004: 128). Para Antonio Bonet Correa, "La Ciudad Universitaria era [...] un vasto cementerio, un depósito expiatorio y votivo de los héroes españoles", (Bustos Moreno, 1988: 19).

19 Esta investigadora recuerda también que, al terminarse la guerra, las ruinas de la Ciudad Universitaria se convirtieron en lugar de peregrinaje, con la visita del Ministro de Asuntos Exteriores italiano, el conde Ciano, y el traslado de los restos de José Antonio Primo de Rivera desde Alicante, Ibíd., p.87. Véase también, de la misma autora, "Usos políticos y académicos del espacio universitario..." (Rodríguez López, 2015: 5).

20 Carolina Rodríguez López afirma que "las ideas sostenidas [... [en la época de la República], tales como la unidad de ubicación, el emplazamiento elegido y la disposición de los edificios se adaptaban perfectamente a las pretensiones iniciales que el Nuevo Régimen aplicó a este mismo espacio y fueron asumidas con continuidad" (Rodríguez López, 2004: 12). 
"el recorrido por el campus se entendió como un ceremonial político" (Rodríguez López, 2015: 106). En efecto, Pilar Chías Navarro explica que "la preparación del estudiante a la participación en los actos se realizaba a base de irle adentrando en un itinerario didáctico configurado por las arquitecturas" (Chías Navarro, 1983: 185). Según estos proyectos, el recorrido empezaría en el antiguo solar de la Cárcel Modelo (Rodríguez López 2004: 20) a punto de convertirse en el neoherreriano edificio del Ministerio del Aire. Se entraría en la Ciudad Universitaria por un Arco de Triunfo que recordaría la victoria de las tropas de Franco, y se proseguiría por una avenida que llevaría al Paraninfo, con el edificio del Rectorado, símbolo del poder del rector consagrado por la nueva Ley de Ordenación Universitaria de julio de 1943. La nueva Ciudad Universitaria tenía que ser una traducción espacial de las ideas expresadas en esta ley ${ }^{21}$, cuyo objetivo era "marcar el autoritario sello ideológico del Régimen en el ámbito docente y [...] reclamar en el espacio universitario nuevos lugares donde 'materializar' las rígidas ideas que tradicionalmente organizaban la enseñanza superior" (Rodríguez López, 2004: 16-17)22. Carolina Rodríguez López habla de una "auténtica plasmación de los poderes actuantes en la Universidad" en el trazado mismo de los edificios, pensados "según una concepción de impronta falangista, para grandes concentraciones de masas" (Rodríguez López, 2004: 19). Este proyecto es, en suma, un intento de "[trasladar] al plano monumental y arquitectónico" (2004: 19) la ideología falangista y nacional-católica que prevalece en los primeros años de la Autarquía. Sin embargo, el proyecto no se lleva a cabo en su totalidad: por falta de recursos económicos, el Rectorado nunca se construye y el Arco de la Victoria solo se termina en el 1956.

A pesar de que todas las obras no están terminadas, se celebra el 12 de octubre de 1943 en la Ciudad Universitaria. Ese día constituye una puesta en práctica de la ideología que impregna los proyectos de reconstrucción: se aprovecha la arquitectura de este espacio, con sus grandes explanadas, para celebrar un acto multitudinario.
Se decora el campus con arquitecturas efímeras, que crean una verdadera escenografía propicia a este tipo de eventos. Franco en persona preside esta ceremonia de marcado signo religioso -se celebra una misa de campaña en la explanada frente a la Facultad de Medicina, donde se ha levantado una cruz de 18 metros de altura- que sirve también de apertura del curso. En su discurso, Franco subraya el valor simbólico de la reconstrucción de la Ciudad Universitaria: "[los combatientes] quedaron sepultados entre las ruinas, y hoy las ruinas han desaparecido para servir de cimiento a estos colosales edificios, que son ahora como monumentos votivos a la gloria de los muertos"23. Según Carolina Rodríguez López, en la posguerra la Ciudad Universitaria se convierte no solo en "un componente esencial del discurso unificador del franquismo" (2004: 6), sino también en "un escenario [...] [para] la demostración de sus poderes" (2004: 6). Si se retoma el concepto creado por Pierre Nora, esta autora considera que "la Ciudad Universitaria fue para Madrid y para el primer franquismo uno de sus 'lugares de memoria' más sobresalientes" (Rodríguez López, 2004: 235).

\section{FILMAR LAS RUINAS: UN ACTO DE RESISTENCIA}

Por tanto, al terminarse la guerra, el franquismo celebraba este lugar como símbolo de heroísmo, pero cuando Bardem rueda su película, en el curso académico 1948-49, ya no es en absoluto el caso: lo que se celebra es la reconstrucción

\footnotetext{
21 El autor del "Editorial" del número extraordinario de la Revista Nacional de Educación dedicado a las celebraciones del 12 de octubre de 1943 en la Ciudad Universitaria afirma que "Franco ha querido que las líneas de una nueva arquitectura respondan, en el plano físico, al nuevo estilo que la Ley de Ordenación Universitaria había inaugurado para la Universidad española en el ámbito de lo espiritual", p.3.

22 Estos nuevos lugares serían el Templo Universitario, unas capillas en cada facultad, y el Museo de América.

23 "Discurso del Caudillo", Revista Nacional de Educación... op. cit., p.9-10.
} 
emprendida por Franco, que desemboca en una completa "resignificación" del espacio ${ }^{24}$. Hoy en día, la Ciudad Universitaria puede ser un símbolo reversible, un "lugar de memoria" ambivalente. Puede ser tanto un símbolo de la defensa republicana de Madrid y del “¡No pasarán!” como de la victoria final de Franco en la guerra; pero, obviamente, en el contexto del final de los años cuarenta, la memoria republicana es invisible y la Ciudad Universitaria es un símbolo unívoco.

Bardem se opone precisamente a esta invisibilidad de la memoria republicana al rodar Paseo por una guerra antigua: como afirma Juan Francisco Cerón Gómez, es la primera película sobre la Guerra Civil que intenta proponer una visión alternativa a la del discurso oficial y adoptar el punto de vista de los vencidos. En este sentido, Bardem sería un "cineasta-historiador", semejante al "artista-historiador" del que habla Miguel Ángel Hernández-Navarro en su libro $M a-$ terializar el pasado. El artista como historiador (benjaminiano). Según este autor, existen artistas que cuestionan "los procesos de construcción de la historia", de la que "[promueven] interpretaciones críticas”. Estos artistas intentan "elaborar una historia diferente" (2012: 11), interesándose por todo lo que el discurso oficial olvida. En sus creaciones se puede ver una afinidad con el pensamiento de la historia de Walter Benjamin. El filósofo desarrolla la idea de que hay una presencia tangible, material del pasado en el presente, de que literalmente, "el pasado no ha pasado". En efecto, para Benjamin, el pasado siempre afecta al presente, porque el tiempo no es lineal sino abierto. El pasado se condensa en objetos o imágenes, de los que estos "artistas-historiadores" se aprovechan para "[traer] literalmente el pasado al presente", para "[hacerlo] visible, [exponerlo]" (Hernández-Navaro, 2012: 18) y para escribir otra versión de la historia. A pesar de que, en su libro, Miguel Ángel Hernández-Navarro estudie principalmente a artistas contemporáneos, nuestra hipótesis es que Bardem es un antecesor de esta corriente artística, ya que Paseo por una guerra antigua es un intento de proponer una visión alternativa de la historia de la guerra civil. Las ruinas de la Ciudad Universitaria condensan el pasado y filmarlas es una manera de revivir este pasado, de traerlo al presente de la posguerra, en un contexto en el que la propaganda franquista quiere, al contrario, crear la imagen de un futuro radiante, a través del programa de reconstrucción.

En el contexto de finales de los años cuarenta, la decisión de Bardem de filmar las ruinas que todavía no han sido transformadas por la reconstrucción no es anodina: es un acto de resistencia, una manera de reapropiarse este espacio en el que el franquismo ha dejado y está dejando su impronta. La película de Bardem va a contracorriente de la ideología que prevalece en la época, ya que filma las ruinas cuando los discursos propagandísticos ya no las elogian, sino que insisten en la reconstrucción. Se podría decir que, precisamente, filmar las ruinas de la Ciudad Universitaria se impone como una necesidad urgente en estos años, porque van desapareciendo a medida que se están llevando a cabo las obras de reconstrucción. Marcel Fortini subraya el hecho de que las ruinas de guerra son efímeras, abocadas a desaparecer cuando se emprende la reconstrucción, momento de su "segunda muerte" (Fortini, 2014: 86). Los escombros de la Ciudad Universitaria no son ruinas cualesquiera: con su desaparición programada, desaparece también una de las últimas huellas de la República y de la guerra civil en el Madrid de la posguerra. Por eso, para un antifranquista como Bardem, es tan importante filmar las ruinas de este lugar. Juega con la función documental del cine: filmar las ruinas es una manera de atestiguar su existencia antes de que los nuevos edificios que la propaganda ce-

\footnotetext{
24 La reconstrucción da lugar a un conjunto de textos propagandísticos: varios fascículos editados por el Ministerio de Educación o por la Universidad Complutense celebran la reconstrucción y contraponen fotografías de las ruinas con otras de los edificios ya reconstruidos. Véanse La Ciudad Universitaria de Madrid, Universidad Complutense, Madrid, 1943; La Ciudad Universitaria de Madrid, Universidad Complutense, Madrid, 1947 y La Ciudad Universitaria. Esquema del trabajo realizado por el Ministerio de Educación Nacional sobre las ruinas heroicas, Ministerio de Educación Nacional, Madrid, 1942.
} 
lebra las sustituyan. También es una manera de atestiguar que la Ciudad Universitaria fue el escenario de un proyecto educativo republicano y emancipador, y de una guerra civil. Es una forma de decir "sí que ocurrió aquí". En este sentido, en el cortometraje de Bardem, el cine se asemeja a la definición que Roland Barthes da de la fotografia: una "magia” que detiene el tiempo.

Atestiguar la existencia de las ruinas mediante el cine es "materializar" el pasado de la República y de la guerra porque las ruinas del campus madrileño son símbolo y sinécdoque tanto de los proyectos republicanos como de la defensa de Madrid. En ellas todavía se pueden ver los trazados de los edificios proyectados. Los escombros son fragmentos que remiten a una forma anterior, a una totalidad perdida ${ }^{25}$, lo que explica que su contemplación pueda provocar cierta melancolía (Lacroix, 2007: 64). En el caso de las ruinas de la Ciudad Universitaria, esta totalidad perdida es el proyecto educativo de la República. La ruina es la prueba de que este proyecto existió, de que se intentó llevarlo a cabo y de que se intentó defenderlo durante la Guerra ${ }^{26}$. Paradójicamente, las ruinas son una "presencia de la ausencia": remiten a un ideal perdido, el ideal republicano, y a su destrucción en la guerra. Filmar esa destrucción es una manera de rescatar la memoria de la República y de la guerra, frente a los discursos propagandísticos que ensalzan la reconstrucción. Por tanto, lo que Bardem propone en Paseo por una guerra antigua es una contramemoria.

\section{UN PASEO ESPACIAL Y TEMPORAL: LA CONTRAMEMORIA DE LA GUERRA CIVIL}

En su cortometraje, Bardem propone una contramemoria de la Guerra Civil porque trae el pasado de la contienda al presente de la posguerra. Se trata de un proceso de "materialización" del pasado al que contribuyen varios elementos de la película.

Primero, es necesario señalar que el título Paseo por una guerra antigua se refiere a un extraño paseo, un paseo que no es espacial sino temporal. El título invita a caminar no por las ruinas de la Ciudad Universitaria sino por la Guerra Civil, como si fuera un viaje por el tiempo. El proyecto de sonorización de la película tenía que cumplir esta función: trasladar al espectador al universo de la guerra, reproduciendo los ruidos de los combates. Además, el título produce una sensación de extrañeza al juntar dos expresiones en apariencia opuestas: no se suele "pasear" por una "guerra". Un título más convencional y lógico sería algo como "Paseo por las ruinas de la Ciudad Universitaria". El hecho de que la expresión "una guerra antigua" haya podido sustituir a "ruinas de la Ciudad Universitaria" muestra que se establece una equivalencia entre ambos elementos: las ruinas de la Ciudad Universitaria son el símbolo de la guerra. No se nombra directamente a la Guerra Civil, se habla de "una guerra antigua", lo cual tiene varios efectos. Se procede a una generalización: las ruinas que el espectador ve podrían ser el fruto de cualquier guerra, la idea subyacente siendo que todas las guerras llevan a la misma destrucción. Con el adjetivo "antigua" se insiste en la distancia, unos diez años, que separa la guerra del momento de la filmación. Parece que es esta distancia temporal lo que impide hablar de "la guerra", lo que obliga a usar el indefinido "una". Si se hablara de "la guerra", significaría que fuera un acontecimiento conocido por todos; al contrario, referirse a la Guerra Civil como "una guerra antigua" quiere decir que se trata de un acontecimiento ya olvidado. La película de Bardem es precisamente una manera de ir en contra de este olvido, "materializando" el pasado.

Paseo por una guerra antigua también es un viaje por el tiempo porque es un viaje por la memoria, por los recuerdos del protagonista. El re-

\footnotetext{
25 Sophie Lacroix considera que la ruina se sitúa "entre el ser y el no-ser, siempre al borde de la desaparición, pero presente en esta forma misma de la ausencia" porque "es a la vez lo que se ve y lo que no se ve, [...] revela ocultando y oculta revelando" (2007: 17). 26 Según Niall Binns se puede hacer una "lectura simbólica" de la defensa de la Ciudad Universitaria, "como una defensa de la cultura", lectura que ya hacían en la época los numerosos intelectuales que se habían alistado en las Brigadas Internacionales (López-Ríos Moreno y González Cárceles, 2008: 601).
} 
sumen que el propio Bardem propone de su práctica muestra que la memoria es lo esencial de la película: "un hombre joven, un mutilado de la Guerra Civil recorre este 'paisaje después de una batalla' y recuerda" (Bardem, 2002: 70-72). La "materialización” del pasado se lleva a cabo mediante un trabajo sobre la memoria en su vertiente más íntima: varios primeros planos del rostro del protagonista muestran su intento por recordar lo que vivió en la Ciudad Universitaria. En dos de estos planos, se le ve cerrar los ojos, como para adentrarse mejor en sus recuerdos. También aparece un primerísimo plano de sus ojos: lo que importa en la película es su mirada personal, afectiva, sobre las ruinas. Para este hombre mutilado, el espacio de la Ciudad Universitaria no es solo un campus estudiantil en fase de reconstrucción, es un espacio que tiene una gran coloración afectiva y que despierta sus recuerdos. También hay varios planos en los que se le ve acercarse a una cruz pequeña, en medio de las ruinas, como si éste fuera un lugar muy significativo y propicio al recuerdo. La sonorización de la película, con los ruidos de las batallas, tendría que haber sido una manera de "materializar" este despertar de los recuerdos y de sumergir al espectador en el flujo de la memoria. Se podría retomar un comentario que formula Miguel Ángel Hernández-Navarro a propósito de la película El Perro negro: Stories from the Spanish Civil War (2004) de Péter Forgács: "Lo personal atraviesa el tiempo colectivo y los afectos penetran en la historiografía desmontando los modos autoritarios, abstractos y canónicos de contar el pasado" (2012: 39). En el caso de Paseo por una guerra antigua, adoptar el punto de vista de un individuo y centrar la película en su relación íntima con el pasado permite proponer una contramemoria, es decir, una alternativa a los discursos grandilocuentes del régimen sobre la cruzada y los flamantes edificios nuevos de la Ciudad Universitaria. Se suele oponer la "memoria", esencialmente afectiva, a la "historia", supuestamente neutra y científica, a veces objeto de manipulaciones. En el cortometraje de Bardem, ya no vale esta oposición: el uso crítico de la memoria cues- tiona la historia oficial para construir otra historia, una historia que también incluye el punto de vista de los vencidos.

Otro aspecto fundamental de Paseo por una guerra antigua y que contribuye a la materialización del pasado es la continua analogía entre las ruinas de la Ciudad Universitaria y la ruina del cuerpo mutilado del protagonista, como si existiese una correspondencia entre el sujeto y el paisaje, el hombre y el espacio. Esta analogía se manifiesta por ejemplo en los planos en los que aparece una estatua ecuestre. Sufrió mucho la contienda: en el cortometraje de Bardem, ya no tiene caballero, solo queda el caballo, sin cabeza. Varios planos crean un juego de eco visual entre la mutilación del caballo y la del protagonista. En uno de estos planos, solo se ven las patas delanteras del caballo y, a la izquierda, en el fondo, mirando la estatua, el mutilado con sus muletas: parece que el caballo de bronce tiene las piernas que al hombre le faltan. En otro de estos encuadres, se muestra la estatua entera con el protagonista en escorzo, mirándola: esta vez, parece que el mutilado tiene la cabeza que a la estatua le falta. Esta analogía entre el mutilado y las ruinas también es perceptible en un plano general en el que se le ve salir de un edificio muy alto, que podría ser una de las ruinas del Hospital Clínico ${ }^{27}$. Una panorámica vertical descendente recorre el edificio hasta llegar hasta él, como si solo fuera una ruina entre las ruinas. De hecho, son muy numerosos los planos generales o de conjunto en los que el mutilado parece formar parte del paisaje de las ruinas. Estos planos en los que se le ve con gran distancia contrastan con los primeros y primerísimos planos de su rostro: sorprende la casi total ausencia de planos figura o planos americanos.

\footnotetext{
27 Llegamos a esta conclusión tras comparar las imágenes de $\mathrm{Pa}$ seo por una guerra antigua con las fotografías de la Ciudad Universitaria en los años cuarenta que aparecen en las publicaciones de la época: La Ciudad Universitaria de Madrid, Universidad Complutense, Madrid, 1943; La Ciudad Universitaria de Madrid, Universidad Complutense, Madrid, 1947 y La Ciudad Universitaria. Esquema del trabajo realizado por el Ministerio de Educación Nacional sobre las ruinas heroicas, Ministerio de Educación Nacional, Madrid, 1942.
} 
La analogía entre hombre y espacio es recíproca: las ruinas del Hopital Clínico pueden ser vistas como un cuerpo mutilado, incluso como un esqueleto ya que lo que queda del edificio es solo su estructura de hormigón armado ${ }^{28}$. Para Marcel Fortini, "el esqueleto de los edificios como un retrato, remite a la imagen del cráneo, símbolo de vanidad" (2014: 89). En este sentido, la representación filmica de las ruinas podría asemejarse a la pintura de vanidades cuya función es recordar al hombre su condición mortal ${ }^{29}$. En todos casos, la "materialización” del pasado culmina con esta analogía entre hombre y espacio: ambos exhiben las huellas de la guerra. Condensan el pasado: Marcel Fortini escribe que "la ruina es [...] un fragmento de la guerra” (2007: 127), también lo es el hombre mutilado de Paseo por una guerra antigua. Además, se podría establecer otra analogía, con la propia película, que ha llegado hasta nosotros en un estado ruinoso ya que solo se conservan fragmentos de un copión y fragmentos de negativo, ambos sin montar.

Como sugiere Sophie Lacroix, la naturaleza fragmentaria de las ruinas remite a una totalidad perdida ${ }^{30}$ : en este caso, esta totalidad puede ser tanto la de la Ciudad Universitaria como proyecto coherente, como la integridad física del protagonista, o como, para el espectador, la integridad de la propia película que, por falta de sonorización y de montaje, no se puede ver tal como la había concebido Bardem. En cuanto al protagonista, varios planos insisten en su mutilación y en su consecuente pérdida de integridad física: son planos que solo muestran su cuerpo desde el tobillo hasta las caderas, centrándose por tanto en su única pierna y sus dos muletas; también hay una panorámica de la sombra de su cuerpo en el suelo, desde el pie hasta la cabeza. Son planos que tienden a deshumanizar al protagonista, ya que muestran partes de su cuerpo como si fueran de cualquiera, sin que se vea su rostro, emblema de su individualidad. Si se comparan estos planos con los ya mencionados primeros planos de su rostro y otros dos primeros planos de cada una de sus manos agarrando las muletas, se puede hablar de una visión fragmen- taria del cuerpo humano: lo que se ve del cuerpo del protagonista son sobre todo partes que parecen estar separadas unas de otras, como si la violencia de la guerra hubiera imposibilitado de manera definitiva el hecho de concebir el cuerpo humano como una totalidad en sí. A estas imágenes de un cuerpo mutilado, se oponen otras, de cuerpos enteros, sanos y en movimiento: cuerpos de los deportistas que estrenan las pistas de atletismo de la recién reconstruida zona deportiva de la Ciudad Universitaria. Igual que el mutilado está en simbiosis con el "erial desfigurado por trincheras y nidos de ametralladoras" (Chías Navarro: 1983, 148) que es la Ciudad Universitaria en la posguerra, estos atletas están en simbiosis con la nueva Ciudad Universitaria que el régimen está reconstruyendo. Hay un primer plano de las piernas en movimiento de un deportista que parece estar lanzando un disco: es un plano que establece un contraste con la mutilación del protagonista pero que, paradójicamente, también tiende a fragmentar el cuerpo del atleta al mostrarlo por partes.

También es necesario mencionar el aspecto gráfico de muchos planos, que convierten la película en un "experimento visual", a veces casi abstracto. Como lo subraya Marcel Fortini, una de las problemáticas esenciales de la representación de las ruinas es la tensión entre el desorden en el que se hallan y el orden que introduce el fotógrafo o el cineasta al elegir un determinado encuadre, es decir, la "coherencia de una visión estética ante el desorden" (Lacroix, 2007: 119). Sin embargo, un acercamiento estético a las ruinas

\footnotetext{
28 Según Pilar Chías Navarro los edificios anteriores al proyecto de Ciudad Universitaria, construidos de forma tradicional, quedaron totalmente destruidos, pero los de hormigón armado, como el edificio de la Facultad de Filosofía y Letras o el Hospital Clínico, todavía tenían su estructura (Chías Navarro, 1983: 145-146).

29 Sophie Lacroix, sin afirmar de forma tan clara como Marcel Fortini que la representación de las ruinas es una forma de memento mori, también se refiere al hecho de que las ruinas "nos [recuerdan] de manera brutal que la destrucción se está llevando a cabo, y que el caos siempre es posible", (2007: 78).

30 "la ruina figura la parte rescatada de un conjunto que está ausente [...]. Lo que queda no nos basta y nos lleva hacia lo que falta" (Lacroix, 2007: 59).
} 
siempre plantea el problema de hasta qué punto se puede ver belleza en la representación de edificios destruidos por una violencia tremenda. En muchos planos se percibe la voluntad estetizante de Bardem, que suele jugar con las líneas, como por ejemplo en un plano general en el que, en primer término, se ven unas barras de metal que salen del suelo y forman una diagonal respecto a las líneas verticales y horizontales de una ruina que se ve en el fondo. También juega mucho con las líneas blancas de la pista de atletismo, que filma con muchísima profundidad de campo ${ }^{31}$. Bardem roza la abstracción en los planos de muros de ladrillo cubiertos de impactos de bala: los filma tan de cerca que los agujeros conforman un verdadero paisaje, un "paisaje después de la batalla".

\section{CONCLUSIONES}

Como sugiere Juan Francisco Cerón Gómez, Paseo por una guerra antigua constituye un intento pionero de evocar la Guerra Civil desde una perspectiva que no es en absoluto la que prevalecía a finales de los años cuarenta. Bardem filma las ruinas de la Ciudad Universitaria en un contexto en el que la propaganda del régimen ensalza la labor de reconstrucción y lleva a cabo una completa resignificación del espacio del campus madrileño. Se trata de un acto de resistencia: con estas imágenes, el joven cineasta inmortaliza unas ruinas que condensan el pasado de la República y de la guerra, ya que simbolizan tanto el proyecto educativo republicano como la defensa de Madrid. Propone al espectador no solo un paseo por las ruinas, sino un paseo por los recuerdos de este mutilado. Las imágenes de la película materializan el pasado y proponen una contramemoria de la Guerra Civil: una visión íntima y melancólica que se opone a los relatos oficiales grandilocuentes.

31 Estos planos anuncian una secuencia de La muerte de un ciclista (Juan Antonio Bardem. 1955): cuando Juan se despide de Matilde y le entrega su carta de dimisión, las pistas de atletismo de esta zona de deportes de la Ciudad Universitaria aparecen con la misma profundidad de campo. 


\section{BIBLIOGRAFÍA}

BARDEM, Juan Antonio. Y todavía sigue, Ediciones B, S.A., Barcelona, 2002.

BARTHES, Roland. "La chambre claire: note sur la photographie", Cahiers du cinéma Gallimard, Paris, 1980.

BENJAMIN Walter. Sur le concept d'histoire suivi de Eduard Fuchs, le collectionneur et l'historien suivi de Paris, la capitale du XIXème siècle, trad. Olivier Mannoni, Editions Payot et Rivages, Paris, 2013.

BONET CORREA, Antonio. "La Ciudad Universitaria de Madrid: realidad y utopía de un proyecto para la modernización cultural de España", en BUSTOS MORENO, Carlos (dir.). La Ciudad Universitaria de Madrid, Colegio Oficial de Arquitectos de Madrid y Universidad Complutense, Madrid, 1988.

--- (coord.), Arte del franquismo, Cátedra, Madrid, 1981.

BUSTOS MORENO, Carlos (dir.). La Ciudad Universitaria de Madrid, Colegio Oficial de Arquitectos de Madrid y Universidad Complutense, Madrid, 1988.

CALVO GONZÁLEZ-REGUERAL, Fernando. La Guerra Civil en la Ciudad Universitaria, Ediciones La Librería, Madrid, 2012.

CAMPOS CALVO-SOTELO, Pablo. 75 años de la Ciudad Universitaria. Memoria viva de un campus trascendental, Editorial Complutense, Madrid, 2004.

CASTRO, Antonio. Testimonio y compromiso. El cine de Juan Antonio Bardem, Ediciones JC, Madrid, 2013.

CERÓN GÓMEZ, Juan Francisco. El cine de Juan Antonio Bardem, Secretariado de Publicaciones Universidad de Murcia y Primavera Cinematográfica de Lorca, Murcia, 1998.

CHÍAS NAVARRO, Pilar. La Ciudad Universitaria de Madrid: Planeamiento y Realización, Tesis Doctoral, Universidad Politécnica de Madrid, Escuela Técnica Superior de Arquitectura, 1983, [http://oa.upm.es/10629/1/Chias_V1_ opt.pdf] Consultado el día: 28.12.2015.

DEL AMO Alfonso (edición a cargo de, con la colaboración de IBAÑEZ María Luisa), Catálogo general del cine de la Guerra Civil, Madrid, Cátedra/Filmoteca Española, 1996.

DIÉGUEZ PATAO, Sofía. "Destrucción, reconstrucción y nuevo carácter de la Ciudad Universitaria. Años cuarenta", en BUSTOS MORENO, Carlos (dir.). La Ciudad Universitaria de Madrid, Colegio Oficial de Arquitectos de Madrid y Universidad Complutense, Madrid, 1988.

FERNÁNDEZ DE SEVILLA MORALES, Miguel. La Ciudad Universitaria de Madrid, 80 años de Historia, Edisofer S.L., Madrid, 2008.

FORERO-MENDOZA, Sabine. Le temps des ruines. L'éveil de la conscience historique à la Renaissance, Champ Vallon, Seyssel, 2002.
FORTINI, Marcel. L'esthétique des ruines dans la photographie de guerre. Beyrouth, centre-ville, une commande exemplaire, L'Harmattan, Paris 2014.

HERNÁNDEZ-NAVARRO, Miguel Ángel. Materializar el pasado. El artista como historiador (benjaminiano), Editorial Micromegas, Murcia, 2012.

LACROIX, Sophie. Ce que nous disent les ruines. La fonction critique des ruines, L'Harmattan, Paris, 2007.

LLINÁS, Francisco (ed.). 50 años de la escuela de cine, Filmoteca Española, Instituto de la Cinematografía y de las Artes Audiovisuales, Ministerio de Educación y Cultura, Cuadernos de la Filmoteca, n4, Madrid, 1999.

LLORENTE, Ángel. "La Ciudad Universitaria de Madrid como género artístico: representación y poder durante dos dictaduras", comunicación pronunciada en el Congreso Internacional "Los Paisajes de guerra - Huellas, reconstrucción, patrimonio (1939 - años 2000)" en la Casa de Velázquez (6, 7, 8 de mayo de 2015): [http:// www.paisajesdeunaguerra.es/podcast/news/la-ciudaduniversitaria-de-madrid-como-genero-artisticorepresentacion-y-poder-durante-dos-dicta/] Consultado el día: 31.12.2015.

LÓPEZ-RÍOS MORENO, Santiago y GONZÁLEZ CÁRCELES, Juan Antonio (coord.). La Facultad de Filosofía y Letras de Madrid en la Segunda República. Arquitectura y Universidad durante los años 30, Sociedad Estatal de Conmemoraciones Culturales, Ayuntamiento de Madrid, Ediciones de Arquitectura, Fundación Arquitectura COAM, Madrid, 2008.

MONTERDE, José Enrique. "Bardem Muñoz, Juan Antonio", en CASARES RODICIO, Emilio (editor y coordinador). Diccionario del cine iberoamericano: España, Portugal y América, Director de España: Carlos F. Heredero / Eduardo Rodríguez Merchán, Director de América: Iván Giroud, Director de Portugal: João Bénard da Costa, Sociedad General de Autores y Editores, Madrid, 2011, pp.678-686.

MICHONNEAU Stéphane, "Vivre entre les ruines. Belchite, 1937-2014", comunicación pronunciada en el Congreso Internacional "Los paisajes de guerra - Huellas, reconstrucción, patrimonio (1939 - años 2000)" en la Casa de Velázquez (6, 7, 8 de mayo del 2015), [https:// www.casadevelazquez.org/pt/investigacao/podcasts/ noticia/vivre-entre-les-ruines-belchite-1937-2014/] Consultado el día: 04.04.2016.

NAVARRO, Agustín. "Ayudante de Luis en Novio a la vista", Nickel Odeon (3), verano de 1996.

NORA, Pierre (dir.). Les lieux de mémoire, Gallimard, Paris, 1997.

PARDO CANALÍS, Enrique. La Ciudad Universitaria, Instituto de Estudios Madrileños, Madrid, 1959.

---, Revista Nacional de Educación, Número extraordinario, Madrid, octubre de 1943. 
RODRÍGUEZ LÓPEZ, Carolina. "Usos políticos y académicos del espacio universitario: la Ciudad Universitaria de Madrid en el primer franquismo", en BERAMENDI, Justo y BAZ, María Xesús (coord.). Memoria e identidades, VII Congreso da Asociación de Historia Contemporánea, Santiago de Compostela-Ourense, 21-24 de setembro de 2004, CD-Rom.

---, La Universidad de Madrid en el primer franquismo. Ruptura y continuidad (1939-1951), Instituto Antonio de Nebrija de estudios sobre la universidad, Universidad Carlos III de Madrid, Madrid, 2002.

---, Paisajes de una guerra: La Ciudad Universitaria de Madrid, Universidad Complutense de Madrid, Servicio de Publicaciones, Madrid, 2015.

SORIA, Florentino. "Mi Berlanga particular", Nickel Odeon (3), verano de 1996.

TRANCHE, Rafael. "La Ciudad Universitaria: del teatro de operaciones al teatro monumental sobre las ruinas", comunicación pronunciada en el Congreso Internacional "Los Paisajes de guerra - Huellas, reconstrucción, patrimonio (1939 - años 2000)" en la Casa de Velázquez (6, 7, 8 de mayo de 2015): [https://www.paisajesdeunaguerra.es/podcast/news/ la-ciudad-universitaria-del-teatro-de-operaciones-alteatro-monumental-sobre-las-ruina] Consultado el día: 31.12.2015.

VV.AA. La Ciudad Universitaria de Madrid, Junta de la Ciudad Universitaria de Madrid, Madrid, 1961.

VV.AA. La Ciudad Universitaria de Madrid, Madrid, 1927.

VV.AA. La Ciudad Universitaria de Madrid, Universidad Complutense, Madrid, 1943.

VV.AA. La Ciudad Universitaria de Madrid, Universidad Complutense, Madrid, 1947.

VV.AA. La Ciudad Universitaria. Esquema del trabajo realizado por el Ministerio de Educación Nacional sobre las ruinas heroicas, Ministerio de Educación Nacional, Madrid, 1942.

\section{HEMEROTECA DIGITAL}

"Un monumento recuerda a los brigadistas internacionales en Ciudad Universitaria", El País, 22/10/2011: [http://cultura.elpais.com/ cultura/2011/10/22/actualidad/1319234403_850215. html]. Consultado el día: 31.12.2015.

MATHIESON David, "Madrid's dangerous attempt to distort the history of the Spanish civil war", The Guardian, 06/06/2013: [http://www.theguardian.com/ commentisfree/2013/jun/06/madrid-history-anti-fascistresistance]. Consultado el día: 31.12.2015. 